\title{
Identity and Sense of Place of Ghajar Residents Living in Border Junction of Syria, Israel and Lebanon
}

\author{
Shamai Shmuel \\ Tel-Hai College \& Shamir Research Institute, \\ University of Haifa \\ Shemali Ali \\ Tel-Hai College

\section{Gorbatkin Dennis} \\ Shamir Research Institute, \\ University of Haifa \\ Chativ Nadim \\ Tel-Hai College \\ Elachmad Halil \\ Tel-Hai College \\ Ilatov Zinaida \\ Shamir Reaserch Unstitute, \\ University of Haifa
}

Doi: $10.2478 / \mathrm{mjss}-2018-0074$

\section{Abstract}

The study focuses on the sense of place among Ghajar inhabitants. Ghajar is unique in its geographical and ethnic status. It is located in the junction of Israel, Syria and Lebanon. The residents are the only Alawites under Israeli control and are isolated from their ethno-religious center in Syria. Two consecutive quantitative surveys and a qualitative study have been implemented: The first quantitative survey was aimed at determining a variety of aspects and attitudes of Ghajar residents towards Israel and towards their village. The second quantitative survey describes the national identity of the residents towards Israel, Lebanon, Syria, and Ghajar. The results represent complicated and instrumental feelings towards Israel, and a very clear and positive attachment toward Syria and towards their village.

Keywords: Borders, Sense of Place, Ghajar, Alawites. Israel, Syria

\section{Introduction}

Throughout history, changes of political borders have been part of the evolution and coexistence of communities. As the residence status of border places changed, rulers had to adopt different strategies to cope with the changing allegiances.

The modern epoch of boundary delimitation in the Middle East started in 1916 with Sykes and Picot drawing straight lines over the map of the Levant to mark off the region on a sectarian basis (Osman, 2013). Thus, the subsequent national status of the native inhabitants was subject to 
decisions made by the external administrations of Great Britain and France and the process of interstate differentiation took the lead over the construction of national identity.

\subsection{The Ghajar Story}

The first mention of Ghajar dates from the Ottoman Empire. The village was known as Taranjeh. Its name was changed to Ghajar by the Kurds, which means "gypsy" in Arabic (Kaufman, 2009). Throughout history Alawites have been the predominant group of village residents. Ghajar was one of the three Alawi villages in the region of the Golan Heights while most Alawites lived some hundreds of kilometers away in the northwest of Syria.

In modern times a boundary-marking process between Lebanon and Syria has never been properly conducted in terms of allocation, delimitation, and demarcation. As a result, there are dozens of contested spots along the 375-kilometerlong boundary between Syria and Lebanon (Kaufman, 2001). During the British and French mandates over Palestine, Syria and Lebanon correspondingly, Ghajar was at a tri-border junction. In the judgment of some authors, Ghajar residents developed an identity of "tri-borderlanders" at that time (Khatib \& Khatib, 1990).

In 1967 Israel captured the Golan Heights from Syria. The Israeli army maps placed Ghajar in Lebanon, but according to Lebanese perceptions it belonged to Syria. Thus they refused to help the people who had stayed in the village (about half the village population had left Ghajar). The Syrian army was not a factor after the 1967 war in this area. So the Ghajar Alawites approached Israel and asked to be attached to the occupied territory with the rest of the Golan Heights population. Israel agreed to incorporate Ghajar, and its residents accordingly accepted living under Israeli laws (BenTzur, 1993).

After Israel withdrew its troops from Lebanon in 2000, the "blue line" (the international border) was demarcated through the village territory, so the northern part of the village came under Lebanese control while the southern part remained Israeli (Bar'el, 2009). Today all Ghajar residents hold Israeli citizenship, and some living in the northern part have dual Lebanese and Israeli citizenship (Ash, 2002). A recent newspaper article covering the current situation in the village and attitudes of the villagers, quotes an interview with a Ghajar resident: "We are not Lebanese... we don't have any links to Lebanon". They feel that they are Syrians (Lazareva, 2015). According to Israeli Central Bureau of Statistics (2016), 2,400 people live in Ghajar.

\subsection{Nation States and National Identity}

There is a widespread view that today's world is basically organized in nation states. This implies that one nationality or ethnic group acts as the cohesive force that both holds nation states together and shapes their relationships with other states (Smith \& Kim, 2006). However, the use of the nation state concept is mostly based on ideal types. According to some studies, there are no more than a dozen states in the world that have a perfect state and nation overlap (Hobsbawm, 1996). The concept of national identity came into use to convey the idea of sense of belonging to one state or to one nation.

The basic premise of Anderson's (1983) theory which is the subject of his best known book Imagined Communities is that nationalism is a relatively modern phenomenon that appeared as a result of the fusion between the decline of religion, human diversity, the development of capitalism and the spread of vernacular languages and printing technology. The process initially started at the time of the Industrial Revolution in Europe and was easily transplanted to the rest of the world. Imagined political communities are both limited and sovereign. They are imagined because members cannot all know each other; limited because no nation encompasses all of mankind, nor even aspires to; and sovereign because nations came into being during Enlightenment and strove for freedom. We call them "communities" because nations are conceived of as a horizontal comradeship of equals.

In order to operationalize the notion of national identity the most likely primal approach is that a person's attachment to a nation is both defined from within - through imagined commonalities and from outside the group (Triandafyllidou, 1998). 


\subsection{Sense of place}

The term sense of place has been discussed in the literature in a variety of ways. There are different approaches to describe the attitudes of people towards the places they live and there are different terms to describe these attitudes. The term "place" itself is also a vague term and is 'dimensionless': it can apply to any scale, from an individual home to any part of the globe; for example, homes, villages and countries are places (Shamai, et al., 2011). Often places are imagined in spite of the fact that people reside in them because they are large in scale, like modern countries that are too large for personal acquaintance among its people. They can also be imagined for people who do not live in them. These are utopian places, that people glorify and where people wish to live or at least declare so.

Place is a "neutral space", but sense of place is not neutral. Sense of place transforms "tabula rasa" into its character by the process of socialization. Sense of place is composed of symbols, cultural values and personal and group perceptions and experiences. When a person has lived in the same place for a long period of time, s/he "often develops a sense of place, feeling at home and secure there, with feelings of belonging for the place being one anchor for his or her identity" (Convery, et al., 2012, p. 3). Sense of place implies an individual's emotional and symbolic identification with a place (Stefanovic, 1998).

Cross (2001) argues that we can create a more meaningful understanding of people's attachments to places by thinking about relationships to place and community attachments as two separate but related aspects of sense of place.

Sense of place is also a dynamic term; one may change his/her feelings towards the same place according to changes during one's lifetime due to changes in one's personal situation and point of view. Shamai and llatov (2005) point out that our race, class and gender affect our interaction with the place.

\section{Methods}

Primary research questions:

1. What are the attitudes of Ghajar residents towards Israel and Ghajar, in general and in terms of age, education and religiousness?

2. What is the intensity of Ghajar residents' sense of place toward their village and toward Israel, Syria and Lebanon?

3. What are the relations among sense of place scores of the places probed? (Ghajar, Israel, Syria and Lebanon.

\section{Research Settings and Samples}

The study was conducted in Ghajar. Due to political sensitivity the research is composed of three unrelated stages. On the first stage we used a random sample of 150 residents (approximately $12.7 \%$ of the adult population (CBS, 2015)). The sample was composed of 80 men and 70 women. The second stage was qualitative and involved 10 people. A random sample of 130 residents was used in the third stage $(11 \%$ of the adult population (Ibid.)). The sample was composed of 67 men and 54 women. The first two stages were conducted in 2014, and the third in 2015.

\section{Research Tool}

The (first) research stage, implemented in 2014, was mainly dedicated to the study of attitudes towards Israel. We used a self-administered questionnaire survey. The socio-demographic characteristics were represented by questions related to sex, age; education (ranging from 1-no education to $6=\mathrm{PhD}$ ) and religiousness of the respondents (yes/no). They were also asked about their marital status and as $136(90.7 \%)$ were married, we did not use this variable. Twenty-seven statements (Table 1) were designed to investigate Israel-related attitudes. We used a five-point ordinal scale with the following categories: (1) full rejection, (2) dissatisfaction, (3) neutrality, (4) 
satisfaction, (5) full acceptance.

The research theme of the third stage (2015) was dedicated to sense of place. We used the same method of a self-administered questionnaire survey. The study of socio-demographic characteristics was limited to age, sex, and education. To measure Ghajar residents' sense of place we used the Shamai and Ilatov (2005) scale that considers sense of place as having different intensity levels, ranging from highly positive $(+5)$ to very negative $(-5)$ feelings.

According to the first research question we analyzed the first survey questions as in

Table 1. The statements means and S.D.

\begin{tabular}{|l|c|c|}
\hline Questions & Mean & Std. Dev. \\
\hline 1. I respect the laws of the state. & 4.48 & 0.642 \\
\hline 2. I am worried about risks to the State of Israel. & 3.93 & 1.021 \\
\hline 3. I am well established in Israel. & 3.63 & 1.065 \\
\hline 4. I feel satisfied with the place where I live. & 3.63 & 1.156 \\
\hline 5. I recognize the importance of being an Israeli citizen. & 3.42 & 1.154 \\
\hline 6. I feel comfortable living in Israel. & 3.32 & 1.058 \\
\hline 7. I feel discriminated against in the State of Israel. ${ }^{*}$ & 3.28 & 1.136 \\
\hline 8. I would like to keep on living in the State of Israel. & 3.27 & 1.284 \\
\hline 9. I would rather live in another country. ${ }^{*}$ & 3.25 & 1.332 \\
\hline 10. The state invests enough resources in my village in comparison with other areas. & 3.01 & 0.980 \\
\hline 11. I would rather not tell anybody that I am an Israeli. ${ }^{*}$ & 2.97 & 1.356 \\
\hline 12. I feel safe in my area. & 2.93 & 1.309 \\
\hline 13. The degree of my integration in Israel is high. & 2.89 & 1.063 \\
\hline 14. I have Jewish friends. & 2.83 & 1.528 \\
\hline 15. The state of Israel has given me all the essential resources for my personal and & 2.81 & 1.079 \\
\hline professional fulfillment. & 2.77 & 1.265 \\
\hline 16. I feel obligated to the State of Israel. & 2.75 & 1.055 \\
\hline 17. I have full rights in this country. & 2.61 & 1.456 \\
\hline 18. I identify myself with Israel. & 2.58 & 1.302 \\
\hline 19. I feel a sense of belonging to the State of Israel. & 2.58 & 1.025 \\
\hline 20. I am proud to be a citizen of the State of Israel. & 2.51 & 1.289 \\
\hline 21. I feel an integral part of the State of Israel. & 2.46 & 1.309 \\
\hline 22. I feel proud while the Israeli flag is raised. & 2.21 & 0.971 \\
\hline 23. I am like other citizens in Israel. & 2.17 & 1.052 \\
\hline 24. The state treats all its citizens equally. & 1.73 & 1.121 \\
\hline 25. If I have the opportunity to serve the country I will use it. & 1.65 & 0.921 \\
\hline 26. I identify myself with the village of Ghajar and not with the state of Israel. ${ }^{*}$ & 1.27 & 0.741 \\
\hline 27. If I were invited to live in some other place within Israel I would agree. & & \\
\hline
\end{tabular}

${ }^{*}$ Scores were reversed for standardization.

From this table it is very clear that their perception of their village is highly positive, while their perception of Israel is quite mixed. When we focus on the two extremes of the scale (means $>3.5$ compared to means<2.5), we learn (from the five highest statements) that they obey Israeli law and manage quite well in Israel, and are also disturbed when Israel is at risk. However. they feel that they belong mainly to their village and not to Israel, and they feel satisfied in their village. From the five lowest (according to their means), statements we learn that they feel that they are not equal to Israelis, and thus it is not surprising that they do not feel pride in the Israeli flag, and are not inclined to serve Israel. When we analyze the other statements, we find although that they do receive equal rights they do feel discriminated against in Israel. They do not feel that they belong to the State of Israel, nor do they feel that they have Israeli identity. Nevertheless. it is clear that Israeli citizenship is important to them and they would like to live in Israel.

These views portray instrumental relations towards Israel. Ghajar residents are not proud of their affiliation with Israel, nor do they feel part of Israeli society and its symbols but it is important for them to live in a secure place like Israel.

Gender differences with regard to the 27 questions were probed. Only with regard to three 
questions were significant differences found. Thus, the overall conclusion is that there are no gender differences ( $\mathrm{N}=70$ females and 80 males). In two out of the three questions in which the gender gaps were significant, women had higher scores: "My Israeli identity" (females mean=2.91; males mean=2.34; $p=0.015$ ) "I'm proud when the Israeli flag is raised" (females mean=2.73; males mean=2.23; $p=0.018$ ). The only question for which the males had a significantly higher score was "I have Jewish friends" (females mean $=2.30$; males mean $=3.30 ; p=0.000$ ). Thus, the actual greater exposure of the males to Israeli society leads to less identification with the Israeli-Jewish identity and its symbols.

In order to further probe the first research question, we examined the differences in attitudes towards Israel and Ghajar according to age and education level and religiousness (based on the first questionnaire). We used cluster analysis to determine attitudes towards Israel among different Ghajar socio-demographic profiles. The analysis was conducted with the standard scores (z-scores) of twenty-seven variables from the corresponding questionnaire data, using the $k$-means method. This method requires an arbitrary specification of the number of clusters. Our most general theoretical assumption was that both in the Ghajar community and in the sample there would be two groups of residents differing in stable sets of predominantly negative or positive attitudes towards Israel.

Choosing a cluster solution by comparing different k-means cluster model outputs, we examined 2, 3, 4, 5-cluster models (see Table 2). A relatively representative number of cases in each cluster within the models were observed only in the three- and two-cluster models. Having examined the data structure of the cluster solutions, a two-cluster model was chosen as most informative. The results of the final $k$-means cluster analysis procedure are summarized in Table 3.

Table 2. Comparison of number of cases in each cluster

\begin{tabular}{|c|c|c|c|c|c|c|c|}
\hline \multicolumn{2}{|c|}{ Two clusters } & \multicolumn{2}{c|}{ Three clusters } & \multicolumn{2}{c|}{ Four clusters } & \multicolumn{2}{c|}{ Five clusters } \\
\hline Cluster 1 & 91 & Cluster 1 & 76 & Cluster 1 & 16 & Cluster 1 & 50 \\
\hline Cluster 2 & 59 & Cluster 2 & 36 & Cluster 2 & 8 & Cluster 2 & 2 \\
\hline Cluster 3 & & Cluster 3 & 38 & Cluster 3 & 77 & Cluster 3 & 37 \\
\hline Cluster 4 & & Cluster 4 & & Cluster 4 & 49 & Cluster 4 & 4 \\
\hline Cluster 5 & & Cluster 5 & & Cluster 5 & & Cluster 5 & 57 \\
\hline
\end{tabular}

Table 3. K-means cluster analysis results (two cluster solution)

\begin{tabular}{|c|c|c|c|c|c|c|c|}
\hline \multirow{3}{*}{ Cluster } & $\begin{array}{r}\text { Distance } \\
\text { Clus }\end{array}$ & $\begin{array}{l}\text { en Final } \\
\text { ters }\end{array}$ & \multirow{3}{*}{$\begin{array}{l}\text { Number of Cases in } \\
\text { each Cluster }\end{array}$} & \multicolumn{4}{|c|}{ Iteration History } \\
\hline & \multicolumn{2}{|c|}{ Cluster } & & \multicolumn{4}{|c|}{$\begin{array}{c}\text { Iterations and Change in Cluster } \\
\text { Centers }\end{array}$} \\
\hline & 1 & 2 & & 1 & 2 & 3 & 4 \\
\hline 1 & & 5.156 & 91 & 6.243 & 0.106 & 0.063 & 0.000 \\
\hline 2 & 5.156 & & 59 & 5.982 & 0.171 & 0.098 & 0.000 \\
\hline
\end{tabular}

These two clusters were used to describe the respondents' attitude tendency together with their socio-demographic profiles for each cluster and to compare the clusters (based on the first questionnaire). To simplify data processing we transformed the interval scale of age into two ordinal scales. The first is based on the median value (Median=47; Mean=49.76; Minimum=19; Maximum=87) and has two categories: "0-47" and "48+". The second divides the interval into three groups: "0-35"; "36-59"; and "60+". For the scale of education, we also transformed the responses related to different degrees of higher education into one group.

Socio-demographic profiles of the clusters. For the ordinal and categorical variables represented in socio-demographic data and cluster membership, we did cross tabulation with chi square analysis. Statistically significant relationships $(p<0.05)$ were identified for age (for both scales), education, and religiousness, but not identified for sex (see Table 4a, b).

Age. The first cluster is represented by noticeably older respondents: $64.8 \%$ of the cluster are 47 years old and older, $53.8 \%$ are 60 years old and older, while only $23.1 \%$ are 35 years old and younger. In the second cluster, $62.7 \%$ of the respondents are $36-59$ years old, $78.0 \%$ are 47 and younger and only $3.4 \%$ are 60 years old and older. 
Religiousness. Only $15.3 \%$ of total sample declared themselves as religious. More than onefifth of the first cluster members were religious while only $6.8 \%$ of respondents from the second cluster gave positive responses.

Education. More than one third of respondents in the first cluster reported that they had no formal education. Together with those who had only elementary education, they constituted almost two thirds of the first cluster. In the second cluster, $37.3 \%$ of of respondents had higher education. Together with vocationally educated respondents they constituted $60.7 \%$ of the cluster members. The share of non-educated was only $10.2 \%$ within the cluster.

We can see some distinctive differences between the socio-demographic profiles of Ghajar residents' clusters. In general, the first cluster is represented by noticeably older, less educated and more religious respondents; the second cluster is represented by substantively younger, more educated and less religious respondents.

In the second stage of cluster content description, we performed cross tabulation with chi square analysis between cluster membership of respondents and twenty-seven variable scores representing the survey question responses. We obtained statistically significant relationships between cluster membership and most variables except questions \#2, 24, 19, 4 (see Appendix 1a to 1 e for details). The main difference in attitudes between the two clusters, represented by most of the corresponding responses, may be formulated thus: The maximum share of positive responses, rarely accompanied by neutral ones, within cluster membership is typical for the second cluster of our study. The maximum percentage of negative responses, in some cases shared with neutral ones, is typical for the first cluster members. We also found some particular tendencies. For the variables concerning the degree of acceptance of the following statements: 1) A sudden and urgent necessity to serve the country (\#8) and 2) equal affiliation with both Ghajar and the country of citizenship (Israel) (\#26); we found a noticeable overbalance of negative responses with the fewest positive ones in the first cluster together with a predominantly negative but more uniform percentage in the second cluster as well. The variable concerning respect for the state laws (\#1) carried no negative scores in both clusters but the highest frequency of full acceptance of this statement $(78 \%)$ was in the second cluster while the number of moderate and extreme scores is almost equal in the first cluster.

In order to summarize the study of Ghajar residents' attitudes, we have proposed the "Index of Israeli Loyalty" as a generalized measure and integrative description (See Appendix 2.) The index was transformed from an interval scale into ordinal scale. It is represented by three intervals $(0$; 0.33 ] - least positive, insignificant; $(0.33 ; 0.66$ ] - conditionally average; $(0.66 ; 1]$ - evident, steady (Mean - 0.6875; Median - 0.6852; Minimum - 0.19; Maximum - 0.96). Only $2.7 \%$ of the respondents showed bottom values. Average and top values are represented respectively by $42 \%$ and $53.3 \%$ of the sample. The "positive" shift in responses may in some respects be explained by the "social desirability bias" effect. According to the cross-tabulation results of the personal index scores and the cluster membership, the first cluster is represented by all respondents from the sample that showed the lowest index scores and $63.7 \%$ of respondents in this cluster demonstrated average, reserved, and less definite opinions. In addition, $91.5 \%$ of respondents in the second cluster have the highest values of the index. Based on the abovementioned analysis, we have accepted relationships between age, education level and degree of religiosity of Ghajar residents and their attitudes toward Israel.

Table 4a. Crosstabs of socio-demographic variables and cluster membership

\begin{tabular}{|c|c|c|c|c|c|c|c|}
\hline \multirow{2}{*}{ Cluster } & \multicolumn{2}{|c|}{ Age (a) (\%) } & \multicolumn{3}{|c|}{ Age (b) (\%) } & \multicolumn{2}{|c|}{ Religiousness (\%) } \\
\hline & $0-47$ & $48+$ & $0-35$ & $36-59$ & $60+$ & Yes & No \\
\hline 1 & 35.2 & 64.8 & 23.1 & 23.1 & 53.8 & 79.1 & 20.9 \\
\hline 2 & 78.0 & 22.0 & 33.9 & 62.7 & 3.4 & 93.2 & 6.8 \\
\hline \multicolumn{8}{|c|}{ Pearson Chi-Square } \\
\hline Value & 26.271 & & 42.877 & & & 5.481 & \\
\hline Df & 1 & & 2 & & & 1 & \\
\hline $\begin{array}{c}\text { Asymp } \\
\text { Sig. (2-sided) }\end{array}$ & 0.000 & & 0.002 & & & 0.019 & \\
\hline
\end{tabular}


Table 4b. Crosstabs of socio-demographic variables and cluster membership

\begin{tabular}{|c|c|c|c|c|}
\hline \multirow{2}{*}{ Cluster } & \multicolumn{4}{|c|}{ Education (\%) } \\
\cline { 2 - 5 } & No education & Elementary & Professional & Higher \\
\hline 1 & $\mathbf{3 5 . 2}$ & $\mathbf{2 9 . 7}$ & 17.6 & 17.6 \\
\hline 2 & 10.2 & 28.8 & $\mathbf{2 3 . 7}$ & $\mathbf{3 7 . 3}$ \\
\hline \multicolumn{4}{|c|}{ Pearson Chi-Square } \\
\hline Value & \multicolumn{4}{|c|}{\begin{tabular}{c} 
\\
\hline Df
\end{tabular}} \\
\hline Asymp & \multicolumn{4}{|c|}{0.002} \\
Sig. (2-sided) & \multicolumn{4}{|c}{} \\
\hline
\end{tabular}

In order to probe the second research question (based on the second questionnaire) we examined the intensity of sense of place levels for Ghajar, Israel, Syria and Lebanon. Descriptive statistics for mean, standard deviation, and frequencies of negative responses $(\mathrm{SOP}<0)$ of sense of place variables (SOP) are shown in Table 5.

Table 5. Sense of Place Descriptive Statistics.

\begin{tabular}{|c|c|c|c|c|}
\hline & Number & Mean & Std. Deviation & Frequency (negative) \\
\hline Lebanon & 129 & -0.18 & 2.134 & 20 \\
\hline Israel & 130 & 2.60 & 2.374 & 9 \\
\hline Ghajar & 130 & 4.26 & 2.040 & 6 \\
\hline Syria & 130 & 4.03 & 1.207 & 0 \\
\hline
\end{tabular}

From Table 5 we learn that the highest score for sense of place was given to their village, together with the lowest score of standard deviation and with no negative values. Among the three nations, Syria received the highest score, which is also an absolutely high value. Israel received a positive score, and Lebanon, a neutral one (on the negative side of the scale). From Table 5 we can see that maximum number of negative values was given to Lebanon together with a negative mean value, which is, however, close to neutral, with a relatively large standard deviation. At the same time Syria received no negative values together with a minimum value of standard deviation.

In order to further probe the second research question, we examined the relationships to Ghajar, Israel, Syria and Lebanon in terms of sense of place intensity (based on the second questionnaire). We applied factor analysis to detect the structure of sense of place of Ghajar. The four variables measuring attitudes to Ghajar, Israel, Lebanon, and Syria correspondingly constituted a two-factor model based on principal components analysis. The factor analysis results are shown in Table 6.

Table 6. Factor Analysis Results

\begin{tabular}{|cccc|}
\hline & FACTOR 1 & FACTOR 2 & Communality \\
\hline SOP Ghjar & .851 & .216 & .770 \\
SOP Israel & .845 & -.008 & .714 \\
SOP Syria & -.084 & .962 & .932 \\
SOP Lebanon & -.427 & .225 & .233 \\
\hline Eigenvalue & 1.626 & 1.023 & \\
\% of Var & 40.661 & 25.566 & \\
Cumulative \% & 40.661 & 66.227 & \\
\hline
\end{tabular}

The component variables with significant values of correlation grouped in the first factor are SOP to Ghajar and Israel while the second factor is represented by SOP to Syria alone. This tendency may be explained in terms of different types of sense of place. These two meaningfully diverse groups of variables (factors) caused us to accept the presence of a structural relationship among the studied sense of place components. This division may reflect the difference between an imagined place, 
where they do not live (Syria) to the two places where they actually reside (Ghajar and Israel), or between utopia and reality.

In the second research question, we examined the intergroup differences in sense of place regarding categories of education (based on the second questionnaire). In order to probe the intergroup differentiation for education we transformed the ordinal scale of "education" into a binominal according to the median value which was "(senior) high school". The first group of the binary education variable was represented by those who had received a secondary school education at most, while the second group was represented by the respondents who had obtained any vocational or higher education. A two-sample t-test was conducted for all "sense of place" (SOP) variables as independent and binary "education" as dependent variables. It was statistically significant: Ghajar SOP $(p<0.05)$ (see Table 7). Thus, the least educated group has highest mean values of SOP towards their village. This result was also supported by a bivariate correlation which was statistically significant $(p<0.05)$ with a negative Spearman's rank correlation coefficient score for "education" and Ghajar (see Table 8). Presumably, this can be explained by the limitations of the least educated groups of population regarding mobility in modern society; these educational limitations also erect barriers to integration into new types of civic communities.

Table 7. T-test results for SOP and categories of education.

\begin{tabular}{|c|c|c|c|c|c|}
\hline \multirow{2}{*}{ Place } & \multirow{2}{*}{ Group } & \multirow{2}{*}{ Mean } & \multirow{2}{*}{ Std. Deviation } & \multicolumn{2}{|c|}{ T-test for Equality of Means } \\
\hline & & & & $\mathrm{T}$ & Sig. (2-tailed) \\
\hline \multirow{2}{*}{ Ghajar } & 12 years of education or less & 4.75 & 1.070 & \multirow{2}{*}{3,025} & \multirow{2}{*}{0.004} \\
\hline & More than 12 years of education & 3.46 & 2.873 & & \\
\hline \multirow{2}{*}{ Israel } & 12 years of education or less & 2.65 & 2.093 & \multirow{2}{*}{0.309} & \multirow{2}{*}{0.758} \\
\hline & More than 12 years of education & 2.50 & 2.845 & & \\
\hline \multirow{2}{*}{ Syria } & 12 years of education or less & 4.24 & 1.024 & \multirow{2}{*}{1.747} & \multirow[b]{2}{*}{0.083} \\
\hline & More than 12 years of education & 3.86 & 1.309 & & \\
\hline \multirow{2}{*}{ Lebanon } & 12 years of education or less & -0.21 & 1.974 & \multirow{2}{*}{0.221} & \multirow{2}{*}{0.825} \\
\hline & More than 12 years of education & -0.30 & 2.476 & & \\
\hline
\end{tabular}

Table 8. SOP/Education Correlations.

\begin{tabular}{|c|l|c|}
\hline & \multicolumn{2}{|c|}{ Education } \\
\hline \multirow{2}{*}{ SOP Ghajar } & Spearman Correlation & $\mathbf{- 0 . 3 1 7}$ \\
\cline { 2 - 3 } & Sig. (2-tailed) & 0.000 \\
\hline \multirow{3}{*}{ SOP Israel } & $\mathrm{N}=117$ & 0.064 \\
\hline \multirow{3}{*}{ SOP Syria } & Spearman Correlation & \\
\cline { 2 - 3 } & $\mathrm{N}=118$ & 0.494 \\
\cline { 2 - 3 } & Sig. (2-tailed) & -0.138 \\
\hline & Spearman Correlation & 0.136 \\
\cline { 2 - 3 } & $\mathrm{N}=118$ & -0.066 \\
\cline { 2 - 3 } & Sig. (2-tailed) & \\
\hline \multirow{3}{*}{ SOP Lebanon } & Spearman Correlation & 0.477 \\
\cline { 2 - 3 } & $\mathrm{N}=117$ & \\
\cline { 2 - 3 } & Sig. (2-tailed) & \\
\hline
\end{tabular}

\section{Qualitative study}

In the second stage of the research, 10 (male) adults were randomly interviewed (The lack of women interviewees was a result of local traditional customs), in order to further probe the possibility of getting sincere answers regarding direct questions about their feelings toward the three countries that surround them. When they were asked about their identity, all of them mentioned Arab and/or Muslim and/or Allawi. Only four mentioned Syrian identity. None mentioned Lebanese or Israeli identity. The main themes that emerged can be summarized by the following statements: "I feel emotionally bound to Syria - my homeland, and to Israel as a good place to live". 
Israel is perceived as a good place where residents enjoy social-national insurance, in contrast to Syria (even before the current civil war), good public health care, and relatively good earning potential. When they were asked if, as Arabs, they feel discrimination in Israel, the following answer is somewhat representative: "I do not feel that there is equality; but I do not feel discrimination". However, most respondents did say that they felt discrimination, particularly when looking for a job.

When they were asked about their future, their answers were definite: We do not care much who will govern the village, but we do not want Ghajar to be divided. Their concern totally revolved around international borders crossing through the village. The following are two typical answers: "I will stay in my home regardless of what country governs the village". "I'm staying in the village because my main circle of belonging is my village and my family". After conducting qualitative study qualitative study stage of the research, we felt that we could move on to asking directly about their feelings towards the three countries.

\section{Results and Discussion}

This study has tried to cast light upon a unique location. Ghajar is geographically located between Israel, Lebanon and Syria. It is Israel's only Alawite village, alienated from the main Alawi population center in Syria. In 1967 residents were divided between those who decided to leave Ghajar and those who decided to stay, meaning that the current residents of the village are the people who actually stayed in place in 1967 and their descendants. Thus, the three stages of this study can be summarized regarding their attitudes toward their own village by a local person who said: "I will stay in my home regardless of what country governs the village". Local patriotism is their survival strategy.

In spite of its uniqueness there has not yet been any academic study of the geography or sociology of this village. According to the first questionnaire, statements referring to Ghajar received higher scores than those referring to issues that relate to Israel. The highest mean values were obtained by statements reflecting the acceptance of Israeli laws and living arrangements. The respondents appreciate the security provided by the state of Israel and express concern for its safety risks. At the same time, the Israeli identity of Ghajar residents is limited to functional issues provided by state institutions in many respects, but the overall sense of equality to other Israelis, acceptance of Israeli symbols and willingness to serve the country are less pronounced. It seems that the current situation in Syria leads them to prefer survival over equality.

Despite the fact that Lebanon received more negative responses than Israel and Ghajar, the mean value of the Lebanon sense of place was close to neutral, with a relatively large standard deviation. Another example of the ambiguity of Lebanon's impact on the Ghajar identity has been demonstrated by our factor analysis results in which Lebanon was the only element uninvolved in the factor model determining the outline of the Ghajar residents' sense of place.

We used cluster analysis to determine attitudes towards Israel among different Ghajar sociodemographic profiles. Two clusters emerged: The first cluster was represented by noticeably older, less educated and more religious respondents; the second cluster was represented by younger, more educated and less religious respondents. Attitudes toward Israel manifested that the maximum percentage of negative responses, in some cases shared with neutral, was typical for the first group. The maximum share of positive responses, rarely accompanied by neutral ones was typical for the second group.

From the second questionnaire, which probed the intensity of sense of place, it was found that the level of sense of place of their settlement was very high. Syria also received a very high score, higher than Israel which scaled in the middle of the positive side of the sense of place scale, which was higher than towards Lebanon (their mean was around neutral). According to factor analysis, the SOP of Israel and Ghajar were combined in the same factor. The other factor is represented by Syria alone. This tendency may be explained in terms of different types of sense of place: Ghajar and Israel represent the reality of daily life while Syria represents a utopian dream.

Statistically significant differences (according to a t-test) were found regarding the level of intensity of sense of place towards Ghajar, with respect to two groups of respondents: a) 12 years of education and less, b) more than 12 years of education. The mean value of Ghajar SOP is higher 
among the less educated group and smaller for the more educated group second. That finding may coincide with the fact that women who are less educated than men $(37 \%$ of the women have postsecondary education, compared to $87 \%$ of the men) have a significantly higher level of sense of place toward Ghajar.

As the Alawi authors of this research describe, "since 2000 the village has been physically disconnected from the world. There is only one entrance to the village, facing Israel. Everywhere you go, you see barbed wire and more barbed wire, and you are surrounded in every direction by the border. The entrance to outsiders is very limited and totally controlled by the Israeli army". But in spite of these difficulties, the sense of security in Israel, particularly relative to Syria, overrides the difficulties. And feelings toward Israel and Syria can be summarized by the words of a local resident: "Syria is my homeland, Israel is our home".

Sense of place usually refers to the place where people reside. However, the imagined sense of place is more powerful than an actual one in this study. Cultural, ethnic, historical and political ties are more important than the actual daily, routine practices. That contrasts with the difficult and tragic situation in Syria compared to life under Israeli control, providing the security of a safe place.

\section{References}

Anderson, B. (1983). Imagined communities: Reflections on the origin and spread of nationalism. London: Verso.

Ash, U. (2002). Ghajar says don't fence me in. Haaretz, 04.06.2002.

Bar'el, Z. (2009). Getting Rid of Ghajar. Haaretz, 10.05.2009.

Ben-Tzur, D. (1993). Interview with Khatib Jamal, a resident of Ghajar. (in Hebrew). Teva Ha-Dvarim, $2^{\text {nd }}$ issue, February-March.

Central Bureau of Statistics (Israel) (2015). Data from the 2008 Population Census. from http://www.cbs.gov.il/census

Convery, I., Corsane, G., \& Davis, P. (2012). Introduction - making sense of place. In Convery, I., Corsane, G. and Davis, P. (Eds.). Making sense of place. N.Y.: Bodyell Press. (pp. 1-10).

Cross, J. (2001). What is sense of place? Prepared for the 12th Headwaters Conference. Western State College, November 2-4, 2001.

Hobsbawm, E. J. (1996). Ethnicity and nationalism in Europe today. In G. Balakrishnan (ed). Mapping the Nation. London: Verso, 255-266. According to Israeli Central Bureau of Statistics (2016) Local Authorities http://www.cbs.gov.il/publications16/local_authorities14_1642/pdf/796_4501.pdf

Kaufman, A. (2001). Who owns the Shebaa farms? Chronicles of a territorial dispute. The Middle East Journal, $56,4,576-596$.

Kaufman, A. (2009). "Let Sleeping Dogs Lie": On Ghajar and other anomalies in the Syria-Lebanon-Israel triborder region. The Middle East Journal, 63, 4, 539-560.

Khatib, A. \& Khatib, J. (1990). Qaryati wa al-Ayam (My Village and the Ages). Nazareth, 9.

Lazareva, I. (2015). Inside the village caught in the crossfire between Israel, Syria and Lebanon. Time, 10.04.2015.

Osman, T. (2013). Why border lines drawn with a ruler in WW1 still rock the Middle East. from http://www.bbc.com/news/world-middle-east-25299553

Shamai, S. (1991). Sense of place: An empirical measurement. Geoforum, 22, 3, 347-358.

Shamai, S., \& Ilatov, Z. (2005). Measuring sense of place: Methodological aspects. Tijdschrift Voor Economische en Sociale Geografie, 96, 5, 467-476.

Shamai, S., Arnon, S., Schnell I., \& Luzon N. (2011). Social issues in Israel sense of place components of the uprooted people of GazaStrip \& north Samaria. Social Issues Israel, 11, 8-40 (Hebrew).

Smith, T. W., \& Kim, S. (2006). National pride in comparative perspective: 1995/96 and 2003/04. International Journal of Public Opinion Research, 18, 127-136.

Triandafyllidou, A. (1998). National identity and the other. Ethnic and Racial Studies, 21, 4, 593-612. 
Appendix 1a. Crosstabs.

\begin{tabular}{|c|c|c|c|c|c|c|c|c|c|c|c|}
\hline & \multicolumn{10}{|c|}{ Statements } \\
\hline & & \multirow{2}{*}{\multicolumn{2}{|c|}{\begin{tabular}{|c|}
5 \\
Clusters
\end{tabular}}} & \multirow{2}{*}{\multicolumn{2}{|c|}{$\begin{array}{c}21 \\
\text { Clusters }\end{array}$}} & \multirow{2}{*}{\multicolumn{2}{|c|}{$\begin{array}{c}9 \\
\text { Clusters }\end{array}$}} & \multirow{2}{*}{\multicolumn{2}{|c|}{$\begin{array}{c}18 \\
\text { Clusters }\end{array}$}} & \multirow{2}{*}{\multicolumn{2}{|c|}{$\begin{array}{c}20 \\
\text { Clusters }\end{array}$}} \\
\hline \multirow{2}{*}{$\begin{array}{l}\prod_{0}^{2} \\
\text { 光 }\end{array}$} & & & & & & & & & & & \\
\hline & & Cl. 1 & Cl. 2 & Cl. 1 & Cl. 2 & Cl. 1 & Cl. 2 & Cl. 1 & Cl. 2 & Cl. 1 & Cl. 2 \\
\hline 1 & $\%$ & 8.8 & 0.0 & 31.9 & 16.9 & 14.3 & 1.7 & 48.4 & 5.1 & 38.5 & 5.1 \\
\hline 2 & $\%$ & 27.5 & 0.0 & 44.0 & 3.4 & 34.1 & 6.8 & 28.6 & 8.5 & 39.6 & 6.8 \\
\hline 3 & $\%$ & 45.1 & 6.8 & 22.0 & 35.6 & 36.3 & 13.6 & 14.3 & 33.9 & 20.9 & 28.8 \\
\hline 4 & $\%$ & 16.5 & 42.4 & 1.1 & 13.6 & 9.9 & 16.9 & 0.0 & 20.3 & 0.0 & 32.2 \\
\hline 5 & $\%$ & 2.2 & 50.8 & 1.1 & 30.5 & 5.5 & 61.0 & 8.8 & 32.2 & 1.1 & 27.1 \\
\hline \multirow{2}{*}{\multicolumn{2}{|c|}{ Test }} & $x^{2}$ & $\alpha$ & $x^{2}$ & $\alpha$ & $x^{2}$ & $\alpha$ & $x^{2}$ & A & $x^{2}$ & $\alpha$ \\
\hline & & 87.6 & 0.00 & 60.2 & 0.00 & 66.0 & 0.00 & 64.0 & 0.00 & 81.8 & 0.00 \\
\hline
\end{tabular}

\section{Appendix 1b. Crosstabs.}

\begin{tabular}{|c|c|c|c|c|c|c|c|c|c|c|c|}
\hline & \multicolumn{10}{|c|}{ Statements } \\
\hline & & \multirow{2}{*}{\multicolumn{2}{|c|}{$\begin{array}{l}2 \\
\text { Clusters }\end{array}$}} & \multicolumn{2}{|c|}{16} & \multicolumn{2}{|c|}{25} & \multicolumn{2}{|c|}{22} & \multicolumn{2}{|l|}{1} \\
\hline \multirow{2}{*}{ 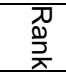 } & & & & \multicolumn{2}{|c|}{ Clusters } & \multicolumn{2}{|c|}{ Clusters } & \multicolumn{2}{|c|}{ Clusters } & \multicolumn{2}{|c|}{ Clusters } \\
\hline & & Cl. 1 & Cl. 2 & Cl. 1 & Cl. 2 & Cl. 1 & Cl. 2 & Cl. 1 & Cl. 2 & Cl. 1 & Cl. 2 \\
\hline 1 & $\%$ & 3.3 & 0.0 & 27.5 & 3.4 & 82.4 & 25.4 & 46.2 & 5.1 & 0.0 & 0.0 \\
\hline 2 & $\%$ & 11.0 & 10.2 & 37.4 & 10.2 & 15.4 & 30.5 & 35.2 & 10.2 & 0.0 & 0.0 \\
\hline 3 & $\%$ & 11.0 & 11.9 & 25.3 & 32.2 & 1.1 & 20.3 & 16.5 & 37.3 & 12.1 & 1.7 \\
\hline 4 & $\%$ & 48.4 & 37.3 & 5.5 & 28.8 & 1.1 & 11.9 & 2.2 & 18.6 & 46.2 & 20.3 \\
\hline 5 & $\%$ & 26.4 & 40.7 & 4.4 & 25.4 & 0.0 & 11.9 & 0.0 & 28.8 & 41.8 & 78.0 \\
\hline \multirow{2}{*}{\multicolumn{2}{|c|}{$\overline{x^{2} \text {-test }}$}} & $x^{2}$ & $\alpha$ & $x^{2}$ & $\alpha$ & $x^{2}$ & $\alpha$ & $x^{2}$ & $\alpha$ & $x^{2}$ & $\alpha$ \\
\hline & & 5.3 & 0.26 & 47.8 & 0.00 & 57.1 & 0.00 & 72.6 & 0.00 & 19.8 & 0.00 \\
\hline
\end{tabular}

Appendix 1c. Crosstabs.

\begin{tabular}{|c|c|c|c|c|c|c|c|c|c|c|c|}
\hline & \multicolumn{10}{|c|}{ Statements } \\
\hline & & \multirow{2}{*}{\multicolumn{2}{|c|}{$\begin{array}{c}7 \\
\text { Clusters } \\
\end{array}$}} & \multirow{2}{*}{\multicolumn{2}{|c|}{$\begin{array}{c}24 \\
\text { Clusters } \\
\end{array}$}} & \multirow{2}{*}{\multicolumn{2}{|c|}{$\begin{array}{c}4 \\
\text { Clusters } \\
\end{array}$}} & \multirow{2}{*}{\multicolumn{2}{|c|}{$\begin{array}{c}10 \\
\text { Clusters } \\
\end{array}$}} & \multirow{2}{*}{\multicolumn{2}{|c|}{$\begin{array}{c}17 \\
\text { Clusters } \\
\end{array}$}} \\
\hline \multirow{2}{*}{ 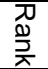 } & & & & & & & & & & & \\
\hline & & Cl. 1 & Cl. 2 & Cl. 1 & Cl. 2 & Cl. 1 & Cl. 2 & Cl. 1 & Cl. 2 & Cl. 1 & Cl. 2 \\
\hline 1 & $\%$ & 12.1 & 5.1 & 35.2 & 30.5 & 5.5 & 11.9 & 2.2 & 6.8 & 14.3 & 3.4 \\
\hline 2 & $\%$ & 11.0 & 11.9 & 37.4 & 16.9 & 7.7 & 6.8 & 31.9 & 15.3 & 40.7 & 18.6 \\
\hline 3 & $\%$ & 44.0 & 23.7 & 20.9 & 35.6 & 23.1 & 20.3 & 52.7 & 37.3 & 34.1 & 47.5 \\
\hline 4 & $\%$ & 27.5 & 30.5 & 5.5 & 13.6 & 46.2 & 28.8 & 8.8 & 22.0 & 8.8 & 11.9 \\
\hline 5 & $\%$ & 5.5 & 28.8 & 1.1 & 3.4 & 17.6 & 32.2 & 4.4 & 18.6 & 2.2 & 18.6 \\
\hline & $x^{2}$ & $\alpha$ & $x^{2}$ & $\alpha$ & $x^{2}$ & $\alpha$ & $x^{2}$ & A & $x^{2}$ & $\alpha$ \\
\hline & & 19.4 & 0.00 & 11.9 & 0.02 & 8.0 & 0.09 & 19.4 & 0.00 & 22.8 & 0.00 \\
\hline
\end{tabular}

Appendix 1d. Crosstabs.

\begin{tabular}{|c|c|c|c|c|c|c|c|c|c|c|c|}
\hline & \multicolumn{10}{|c|}{ Statements } \\
\hline & & \multirow{2}{*}{\multicolumn{2}{|c|}{$\begin{array}{c}12 \\
\text { Clusters }\end{array}$}} & \multirow{2}{*}{\multicolumn{2}{|c|}{$\begin{array}{c}26 \\
\text { Clusters }\end{array}$}} & \multirow{2}{*}{\multicolumn{2}{|c|}{$\begin{array}{c}27 \\
\text { Clusters }\end{array}$}} & \multirow{2}{*}{\multicolumn{2}{|c|}{$\begin{array}{c}13 \\
\text { Clusters }\end{array}$}} & \multirow{2}{*}{\multicolumn{2}{|c|}{6}} \\
\hline \multirow{2}{*}{ 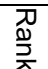 } & & & & & & & & & & & \\
\hline & & Cl. 1 & Cl. 2 & Cl. 1 & Cl. 2 & Cl. 1 & Cl. 2 & Cl. 1 & Cl. 2 & Cl. 1 & Cl. 2 \\
\hline$\hat{1}$ & $\%$ & 11.0 & 25.4 & 65.9 & 49.2 & 91.2 & 71.2 & 16.5 & 1.7 & 8.8 & 1.7 \\
\hline 2 & $\%$ & 35.2 & 6.8 & 27.5 & 13.6 & 6.6 & 18.6 & 35.2 & 3.4 & 17.6 & 1.7 \\
\hline 3 & $\%$ & 16.5 & 33.9 & 6.6 & 27.1 & 0 & 3.4 & 37.4 & 45.8 & 52.7 & 27.1 \\
\hline 4 & $\%$ & 23.1 & 18.6 & 0.0 & 6.8 & 2.2 & 3.4 & 11.0 & 30.5 & 18.7 & 33.9 \\
\hline 5 & $\%$ & 14.3 & 15.3 & 0.0 & 3.4 & 0 & 3.4 & 0.0 & 18.6 & 2.2 & 35.6 \\
\hline & $x^{2}$ & $\alpha$ & $x^{2}$ & $\alpha$ & $x^{2}$ & $\alpha$ & $x^{2}$ & $\overline{A A}$ & $x^{2}$ & $\alpha$ \\
\hline & & 21.5 & 0.00 & 24.4 & 0.00 & 12.7 & 0.01 & 48.2 & 0.00 & 45.9 & 0.00 \\
\hline
\end{tabular}


Appendix 1e. Crosstabs.

\begin{tabular}{|c|c|c|c|c|c|c|c|c|c|c|c|c|c|c|c|}
\hline & \multicolumn{14}{|c|}{ Statements } \\
\hline & & \multirow{2}{*}{\multicolumn{2}{|c|}{$\begin{array}{c}15 \\
\text { Clusters }\end{array}$}} & \multirow{2}{*}{\multicolumn{2}{|c|}{$\begin{array}{c}19 \\
\text { Clusters }\end{array}$}} & \multirow{2}{*}{\multicolumn{2}{|c|}{$\begin{array}{c}14 \\
\text { Clusters }\end{array}$}} & \multirow{2}{*}{\multicolumn{2}{|c|}{$\begin{array}{c}3 \\
\text { Clusters }\end{array}$}} & \multirow{2}{*}{\multicolumn{2}{|c|}{$\begin{array}{c}11 \\
\text { Clusters }\end{array}$}} & \multirow{2}{*}{\multicolumn{2}{|c|}{\begin{tabular}{|c|}
23 \\
Cluster
\end{tabular}}} & \multirow{2}{*}{\multicolumn{2}{|c|}{$\frac{8}{\text { Cluster }}$}} \\
\hline \multirow{2}{*}{$\begin{array}{l}\text { DN } \\
\text { 党 }\end{array}$} & & & & & & & & & & & & & & & \\
\hline & & Cl. 1 & Cl. 2 & Cl. 1 & Cl. 2 & Cl. 1 & Cl. 2 & Cl. 1 & Cl. 2 & Cl. 1 & Cl. 2 & Cl. 1 & Cl. 2 & Cl.1 & $\mathrm{Cl} .2$ \\
\hline 1 & $\%$ & 11.0 & 25.4 & 65.9 & 49.2 & 91.2 & 71.2 & 16.5 & 1.7 & 8.8 & 1.7 & 31.9 & 18.6 & 20.9 & 0.0 \\
\hline 2 & $\%$ & 35.2 & 6.8 & 27.5 & 13.6 & 6.6 & 18.6 & 35.2 & 3.4 & 17.6 & 1.7 & 52.7 & 10.2 & 22.0 & 0.0 \\
\hline 3 & $\%$ & 16.5 & 33.9 & 6.6 & 27.1 & 0 & 3.4 & 37.4 & 45.8 & 52.7 & 27.1 & 15.4 & 50.8 & 41.8 & 8.5 \\
\hline 4 & $\%$ & 23.1 & 18.6 & 0.0 & 6.8 & 2.2 & 3.4 & 11.0 & 30.5 & 18.7 & 33.9 & 0 & 15.3 & 13.2 & 42.4 \\
\hline 5 & $\%$ & 14.3 & 15.3 & 0.0 & 3.4 & 0 & 3.4 & 0.0 & 18.6 & 2.2 & 35.6 & 0 & 5.1 & 2.2 & 49.2 \\
\hline \multirow{2}{*}{\multicolumn{2}{|c|}{ x2-test }} & $x^{2}$ & $\alpha$ & $x^{2}$ & $\alpha$ & $x^{2}$ & $\alpha$ & $x^{2}$ & $\alpha$ & $x^{2}$ & $\alpha$ & $x^{2}$ & $\alpha$ & $x^{2}$ & $\alpha$ \\
\hline & & 21.5 & 0.00 & 24.4 & 0.00 & 12.7 & 0.01 & 48.2 & 0.00 & 45.9 & 0.00 & 54.2 & 0.00 & 89.7 & 0.00 \\
\hline
\end{tabular}

Appendix 2. "Index of Israeli Loyalty".

We constructed a new "negative variable" $\left({ }^{x_{i j}}\right)$ for negative scores, which takes the value "0" if a respondent gives a neutral or positive answer and takes values "1" or " 2 " for "dissatisfaction" and "full rejection" correspondingly. Thus, the personal "Index of Israeli Loyalty ("Index")" ( $\left.L_{j}\right)$ is the difference between the maximum valid score of "Index" ( $\left.L_{\max }\right)$ and the product of the maximum valid score of "Index" with the quotient of the mean value of the respondent's "negative variables" in the row

$$
\left(\frac{\sum_{i=1}^{n} x_{i j}}{n}\right)
$$
interval.

and the maximum valid score of the "negative variable" $\left(X_{\max }\right)$. "Index" varies in the $[0 ; 1]$

$P_{j}$ - Personal "Index of Israeli Loyalty"; G - Local (general) "Index of Israeli Loyalty"

$a_{i j}$ - Individual values of the variables; $x_{i j}$ - Corrected individual values of the variables

$a_{i j} \in[1 ; 5] ; x_{i j} \in[0 ; 2] ; P_{j} \in[0 ; 1]$

$x_{i j}=\left\{\begin{array}{l}0, a_{i j}>2, \\ 1, a_{i j}=2, \\ 2, a_{i j}=1\end{array} \quad L_{j}=L_{\max } \frac{\sum_{i=1}^{n} x_{i j}}{n} \times \frac{L_{\max }}{X_{\max }} ; \quad \mathrm{G}=\frac{\sum_{j=1}^{m} L_{j}}{m}\right.$ 